\title{
Relapse in resected lung cancer revisited: does intensified follow up really matter? A prospective study Dragan Subotic*1, Dragan Mandaric ${ }^{1}$, Gordana Radosavljevic ${ }^{1}$, Jelena Stojsic ${ }^{1}$, Milan Gajic ${ }^{2}$ and Maja Ercegovac ${ }^{1}$
}

Address: ${ }^{1}$ Institute for Lung Diseases, Clinical Center of Serbia, Belgrade, Serbia and ${ }^{2}$ Institute for Medical Statistics, Faculty of Medicine, Belgrade, Serbia

Email: Dragan Subotic* - vilusi@yubc.net; Dragan Mandaric - dmandaric@googlemail.com; Gordana Radosavljevic - milena@drenik.net; Jelena Stojsic - grudhir@yubc.net; Milan Gajic-milgaj@med.bg.ac.rs; Maja Ercegovac-majaerce@verat.net

* Corresponding author

Published: 12 November 2009

World Journal of Surgical Oncology 2009, 7:87 doi:10.1 186/1477-7819-7-87

This article is available from: http://www.wjso.com/content/7/l/87

(c) 2009 Subotic et al; licensee BioMed Central Ltd.

This is an Open Access article distributed under the terms of the Creative Commons Attribution License (http://creativecommons.org/licenses/by/2.0), which permits unrestricted use, distribution, and reproduction in any medium, provided the original work is properly cited.
Received: 19 July 2009

Accepted: 12 November 2009

\begin{abstract}
Background: beside the well known predominance of distant vs. loco-regional relapse, several aspects of the relapse pattern still have not been fully elucidated.

Methods: prospective, controlled study on 88 patients operated for non-small cell lung cancer (NSCLC) in a 15 months period. Stage IIIA existed in 35(39.8\%) patients, whilst stages IB, IIA and IIB existed in $10.2 \%, 4.5 \%$ and $45.5 \%$ patients respectively. Inclusion criteria: stage I-IIIA, complete resection, systematic lymphadenectomy with at least 6 lymph node groups examined, no neoadjuvant therapy, exact data of all aspects of relapse, exact data about the outcome of the treatment.
\end{abstract}

Results: postoperative lung cancer relapse occurred in 50(56.8\%) patients. Locoregional, distant and both types of relapse occurred in $26 \%, 70 \%$ and $4 \%$ patients respectively. Postoperative cancer relapse occurred in $27 / 35(77.1 \%)$ pts. in the stage IIIA and in 2I/40(52.55) pts in the stage IIB. In none of four pts. in the stage IIA cancer relapse occurred, unlike $22.22 \%$ pts. with relapse in the stage IB. The mean disease free interval in the analysed group was $34.38 \pm 3.26$ months.

The mean local relapse free and distant relapse free intervals were $55 \pm 3.32$ and $41.62 \pm 3.47$ months respectively Among 30 pts. with the relapse onset inside the first 12 month after the lung resection, in 20(66.6\%) pts. either T3 tumours or N2 lesions existed. In patients with N0, NI and N2 lesions, cancer relapse occurred in $30 \%, 55.6 \%$ and $70.8 \%$ patients respectively

Radiographic aspect $\mathrm{T}$ stage, $\mathrm{N}$ stage and extent of resection were found as significant in terms of survival. Related to the relapse occurrence, although radiographic aspect and extent of resection followed the same trend as in the survival analysis, only $\mathrm{T}$ stage and $\mathrm{N}$ stage were found as significant in the same sense as for survival. On multivariate, only $\mathrm{T}$ and $\mathrm{N}$ stage were found as significant in terms of survival.

Specific oncological treatment of relapse was possible in $27 / 50(54 \%)$ patients.

Conclusion: the intensified follow up did not increase either the proportion of patients detected with asymptomatic relapse or the number of patients with specific oncological treatment of relapse. 


\section{Background}

Despite the well known predominance of distant vs. locoregional relapse in patients operated for primary NSCLC, several aspects of the relapse pattern still have not been fully elucidated. Data about lung cancer relapse are usually added to long term survival data, mainly without details other than about the form of relapse $[1,2]$. There are few reports specifically addressing the pattern of relapse including exact onset of relapse, the way of detecting relapse (symptom based/controls) and treatment, taking account of tumour and patient related characteristics [3].

We set out to determine if intensified follow up of these patients could influence the outcome of treatment through earlier detection of relapse and initiation of treatment. Our hypothesis was that the reason for treatment failure in many operated patients, independently of the way of preoperative mediastinal assessment, could be the existence of clinically occult micrometastases at the time of operation, leading to early, unrecognized cancer relapse, usually with delayed, if with any specific treatment.

The aim of the study was to assess whether the intensified follow up of the operated patients contributes to the earlier treatment of relapse or indicates the way of improving the preoperative patient selection.

\section{Patients and methods}

Prospective, controlled study that included 88 patients with complete lung resection for NSCLC in the period December 2002 - March 2004.

The mean age of patients was 55 years, ranging 42-77 years, M:F 6.3:1.

Stage IIIA existed in 35(39.8\%) patients, whilst stages IB, IIA and IIB existed in $10.2 \%, 4.5 \%$ and $45.5 \%$ patients respectively.

In the present study, the 1997 revision of TNM system was used in order to determine the disease stage based on the operative specimens of the lung tissue and harvested lymph nodes.

\section{Inclusion criteria}

Stage I-IIIA; complete resection; systematic lymphadenectomy with at least 6 different lymph node groups examined; no neoadjuvant therapy; exact data about tumour histology, tumour diameter, grade of tumour differentiation, visceral pleural involvement, vascular and lymphatic invasion; regular monthly contacts with patients and written report about the patient's status; exact date of the relapse suspicion and confirmation; exact data about the site of relapse; evidence of pathologic confirmation of relapse; precise evidence about treatment of the relapse date the treatment began and ended, form of the treatment; outcome of the treatment (alive and disease free, alive with disease, dead); date of death; cause of death.

\section{Preoperative work up}

Standard clinical and laboratory investigations, bronchoscopy, high-resolution CT of the thorax and upper abdomen, respiratory function tests, blood gasses in the arterial blood.

Mediastinoscopy was not routinely performed in the analysed period.

In patients with moderate to severe COPD), combined bronchodilator therapy, with or without antibiotics was applied. Patients with $\mathrm{FEV}_{1}$ and $100 \mathrm{FEV}_{1} / \mathrm{VC}$ greater than $60 \%$ at control spirometry. were referred directly to surgery. Patients with $\mathrm{FEV}_{1}$ and $100 \mathrm{FEV}_{1} / \mathrm{VC}$ lower than $60 \%$ at control spirometry, were subjected to perfusion scintigraphy of the lungs, in order to calculate the predicted postoperative $\mathrm{FEV}_{1}\left(\mathrm{ppoFEV}_{1}\right)$. They were referred to surgery if their ppoFEV $_{1}$ was greater than $30 \%$ predicted.

\section{Follow up and data analysis}

Follow up period: December 2002-December 2008.

In the analyzed group, an intensified follow+up was applied. The term "intensified follow up" relates to regular monthly phone contacts with patients and/or their families in order to get reliable information about the patient's general condition and eventual new complaints that were not present on discharge. Independently of this follow up, all the included patents were regularly controlled in the outpatient clinic at one month intervals during the first 3 months, than at 3 months intervals till the end of the first postoperative year. During the second and third postoperative year, intensified follow up was combined with regular outpatient controls at 4 months. Further outpatient controls were shaduled at 6 months intervals, combined with intensified follow up as described.

Data were collected from the original patients' hospital and outpatient dossiers and by contacting the patients or their relatives or physicians by phone. The obtained demographic and clinical data, including age, gender, pulmonary function, comorbidity, quality of life after the operation, as well as perioperative data, consisting of surgical procedure, pathologic stage, and operative morbidity and mortality, were entered into the database.

The overall and disease free survival were calculated, as well as local relapse free and distant metastases free sur- 
vival. Disease free survival corresponds to the length of time after the operation during which a patient survives with no signs of disease.

Locoregional relapse-free interval represents the time interval (in months) between the operation and diagnosis of the locoregional relapse. As for this type of relapse, symptoms may not be reliable in terms of the existence of relapse. the moment of the relapse diagnosis by imaging and/or biopsy represented the moment of the relapse onset.

Distamt relapse-free survival refers to the time interval (in months) between the operation and detection of distant metastases. In patients with subsequently confirmed brain or bome metastases, the appearance of first specific symptoms was accepted as the time of the relapse onset.

Cancer relapse inside the first 12 postoperative months was particularly analysed.

Univariate and multivariate analysis of factors influencing the overall survival and the relapse occurrence included: interval between the onset of symptoms and operation, radiographic aspect, bronchoscopic aspect, tumour diameter, T and $\mathrm{N}$ stage, visceral pleural involvement, extent of resection and adjuvant treatment.

\section{Statistics}

T-test for independent samples was used to assess the influence of the Tu diameter to the length of the interval operation-relapse and to the pattern of relapse occurrence (inside the first postoperative year or later).

Chi-square test.was used to assess the influence of the percentage of N2 lesions to the length of the interval operation-relapse and to the occurrence of relapse inside the first postoperative year. year. Also this test was used to assess the distribution of $\mathrm{N} 2$ lesions depending of the type of T2 descriptor. Survival was estimated by the Kaplan Meier method.

Multivariate analysis of prognostic factors was performed via Cox proportional hazard regression with backward elimination until all remaining model parameters were significant at the 0.05 level.

\section{Results}

\section{Structure of the analysed group}

The mean age of patients was 55 years, ranging 42-77 years, M:F 6.3:1.

Stage IIIA existed in 35(39.8\%) patients, whilst stages IB, IIA and IIB existed in $9(10.2 \%), 4(4.5 \%)$ and $40(45.5 \%)$ patients respectively.
There were 38 right sided and 50 left sided tumours. Thirty five patients underwent lobectomy and 53 underwent pneumonectomy.

In $67(76 \%)$ patients squamous cell carcinoma existed. There were 18 patients with adenocarcinoma, one with bronchioloalveolar carcinoma and two with adenosquamous carcinoma. Postoperatively, 23(26.1\%) patients underwent adjuvant therapy (21 irradiation and 2 chemotherapy).

\section{T stage; $\mathbf{N}$ stage}

Of 70 patients with $\mathrm{T} 2$ tumors, tumour diameter $(>3 \mathrm{~cm})$ was the only $\mathrm{T}$ descriptor in $41(58.6 \%)$ patients, visceral pleural involvement was the only $\mathrm{T}$ descriptor in 2 patients, whilst in the remaining $27(38.6 \%)$ patients, both tumour diameter $>3 \mathrm{~cm}$ and visceral pleural involvement existed (table 1). Five different T3 descriptors were almost equally distributed.

Mediastinal lymph node metastases existed in 12(29.35) patients with tumour diameter as the only T2 descriptor and in $9(33.3 \%)$ patients with visceral pleural involvement $(\mathrm{P}>0.8136)$.

Although the survival of patients with T2 tumours and visceral pleural involvement was inferior vs. patients with intact visceral pleura, this survival difference was not sta-

Table I: T-descriptors

T2 tumours

\begin{tabular}{|c|c|c|}
\hline & $\mathbf{n}$ & $\%$ \\
\hline Rtu $>3 \mathrm{~cm}$ & 41 & 58.6 \\
\hline visceral pleura & 2 & 2.8 \\
\hline Rtu> $3 \mathrm{~cm}+$ visceral pl. & 27 & 38.6 \\
\hline total & 70 & 100 \\
\hline T3 tumours & $\mathrm{n}$ & $\%$ \\
\hline chest wall & 4 & 28.6 \\
\hline parietal pleura & 3 & 21.5 \\
\hline mediastinal pleura & 2 & 14.2 \\
\hline pericardium & 3 & 21.5 \\
\hline$<2 \mathrm{~cm}$ from carina & 2 & 14.2 \\
\hline total & 14 & 100 \\
\hline
\end{tabular}


tistically significant-median survival $34 \pm 7$ months vs. 26 \pm 7 months (figure 1 ).

The percent of positivity of the examined mediastinal lymph nodes varied between $2.8 \%$ for pulmonary ligament nodes and $17.8 \%$ for the upper paratracheal nodes. Metastases in hilar, interlobar and lobar lymph nodes were confirmed in $29.5,22.4$ and $81.8 \%$ of examined lymph nodes.

\section{Pattern of relapse; disease free survival}

The type of relapse according to stage is presented on table 2. During the follow up period, postoperative lung cancer relapse occurred in 50(56.8\%) patients. In 44 patients symptoms existed, whilst in 6 asymptomatic patients relapse was detected at regular controls.
Locoregional, distant and both types of relapse occurred in $26 \%, 70 \%$ and $4 \%$ patients respectively. Postoperative cancer relapse occurred in 27/35(77.1\%) pts. in the stage IIIA and in 21/40(52.5) pts in the stage IIB. In none of four pts. in the stage IIA cancer relapse occurred, unlike $22.2 \%$ pts. with relapse in the stage IB.

In patients with N0, N1 and N2 lesions, cancer relapse occurred in $30,55.6$ and $70.8 \%$ patients respectively.

Cancer relapse occurred in 37/67(55.2\%) patients with sqiamous cell carcinoma and in 13/21(62\%) patients with other cell types.

In patients with relapse, well differentiated, moderately and poorly differentiated tumours existed in 10(20\%),

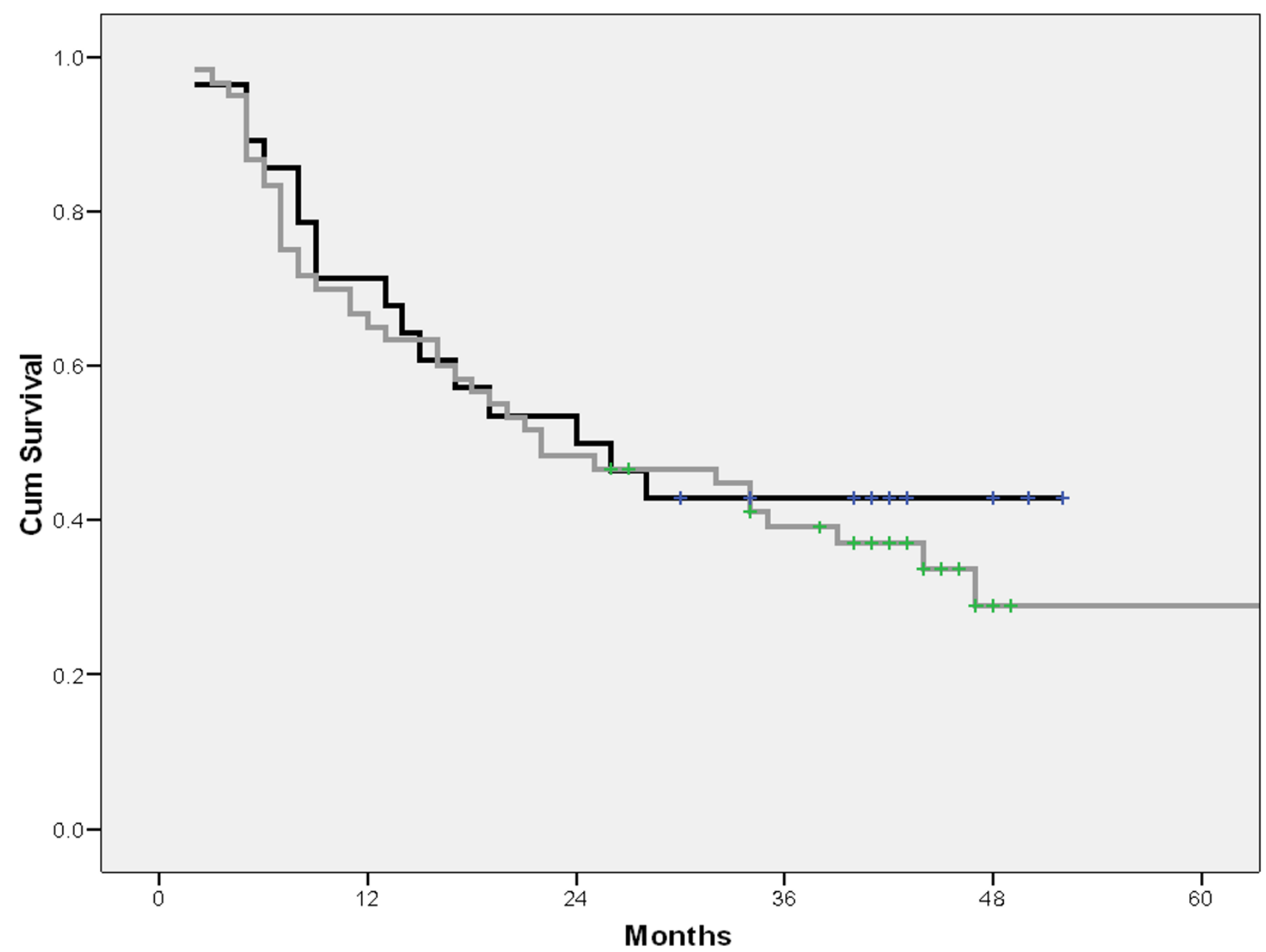

Figure I

Survival depending $\mathbf{n}$ visceral pleural involvement (gray line: visceral pleura intact, black line: visceral pleura invaded). 
Table 2: Type of postoperative cancer relapse

\begin{tabular}{ccc}
\hline LC relapse & $\mathbf{n}$ & $\%$ \\
\hline with symptoms & $44 / 50$ & 88 \\
\hline without symptoms & $6 / 50$ & 12 \\
\hline locoregional & $13 / 50$ & 26 \\
\hline distant & $35 / 50$ & 70 \\
\hline locoreg.+ distant & $2 / 50$ & 4 \\
\hline relapse in IB & $2 / 9$ & 22.2 \\
\hline relapse in IIB & $21 / 40$ & 52.5 \\
\hline relapse in IIIA & $27 / 35$ & 77.1 \\
\hline relapse in pNo & $3 / 10$ & 30 \\
\hline relapse in pNI & $30 / 54$ & 55.6 \\
\hline relapse in pN2 & $17 / 24$ & 70.8 \\
\hline
\end{tabular}

$25(50 \%)$ and $15(30 \%)$ patients respectively. In patients without relapse, the same categories of the grade of tumour differentiation existed in $6(15.9 \%), 24(63.1 \%)$ and $8(21 \%)$ patients respectively.

The overall two, three and 5 year survival was $48.8,40.2$ and $33 \%$ respectively.

The disease free survival is presented on the figure 2. One year after the operation, $62.7 \%$ patients were alive and disease free. Two years after the operation $47.3 \%$ patients were disease free, whilst the percentage of patients without relapse decreased to 41.5 and $37.7 \%$ three and four years after the operation.

The overall disease free interval, local relapse-free and distant relapse-free intervals are presented on the table 3 . The mean disease-free interval in the analysed group was 34.4 \pm 3.2 months (median 19, 95\%CI: 6.62-31.38). The mean local relapse-free and distant relapse-free intervals were 55 \pm 3.3 and $41.6 \pm 3.5$ months respectively.

One year after the operation, $90.4 \%$ patients were without locoregional relapse. Two years after the operation $78.3 \%$ patients were locoregional relapse free, whilst this percentage decreased to $70.7 \%$ four years after the operation (figure 3a). The percentage of distant relapse free patients decreased from $69.4 \pm 5 \%$ one year after the operation, to $50.5 \pm 6.2 \%$ four years after the operation (figure $3 b$ ).

\section{Relapse inside the first postoperative year}

Among 30 pts. with the relapse onset inside the first 12 month after the lung resection, the disease free interval $<3$ months, 3-6 months and $>6$ months occurred in $10(33.3 \%), 12(40 \%)$ and $8(26.7 \%)$ pts. respectively. In $20(66.6 \%)$ pts. in this group, either T3 tumours or N2 lesions existed (table 4). Although the tumour diameter in patients with relapse inside the first postoperative year was $79 \pm 32 \mathrm{~mm}$ vs. $63 \pm 19.8 \mathrm{~mm}$ in patients with later relapse occurrence, this difference was not statistically significant. Mediastinal lymph node metastases existed in $40.6 \%$ patients with relapse inside the first year vs. $22.2 \%$ patients with $\mathrm{N} 2$ lesions and relapse after the first year ( $\mathrm{P}$ : $0.395)$.

\section{Distant metastases}

Among 37 patients with metastases, one single and more than one distant sites existed in $70.27 \%$ and in $29.73 \%$ patients respectively. The most frequent distant site was brain $(51.4 \%$ pts), followed by bone ( $18.9 \%$ pts.), liver and contralateral lung (16.2\% pts. each). Metastases in distant lymph nodes, adrenals and other sites were registered in five, three and two patients respectively.

Although the median disease free interval of 3 months (95\% CI: 0.39-5.61) in patients with brain metastases was shorter than the same interval of 6 months in patients with metastases in other sites, this difference is not statistically significant (P: 0.0735).

\section{Extent of resection; relapse treatment}

The median disease free interval after lobectomy was 36 months vs. 16 onths after pneumonectomy (P: 0.0925). Survival after lobectomy was significantly longer than after pneumonectomy (figure 4).

Specific oncological treatment of relapse was possible in $27 / 50(54 \%)$ patients. Fourteen patients underwent radiation therapy only; in 9 patients operative treatment was performed, either as the only treatment modality (two patients) or in combination (5 OP+RT, $2 \mathrm{OP}+\mathrm{CT}+\mathrm{RT}$ ). Chemotherapy alone was given to two patients, whilst one patient underwent chemotherapy combined with radiation therapy.

\section{Univariate and multivariate analysis of prognostic factors} Univariate analysis of factors influencing survival and relapse occurrence are presented on the table 5. Radiographic aspect (tumour shadows vs. other categories), $\mathrm{T}$ stage ( $<\mathrm{T} 3$ vs T3), N stage (N0/N1vs. N2) and extent of resection (lobectomy vs. pneumonectomy) were found as significant in terms of survival. Symptom duration longer than three months (vs. $<3$ months) and tumour diameter $<5 \mathrm{~cm}$ (vs. $>5 \mathrm{~cm}$ ) were associated with better survival, but without statistical significance. 


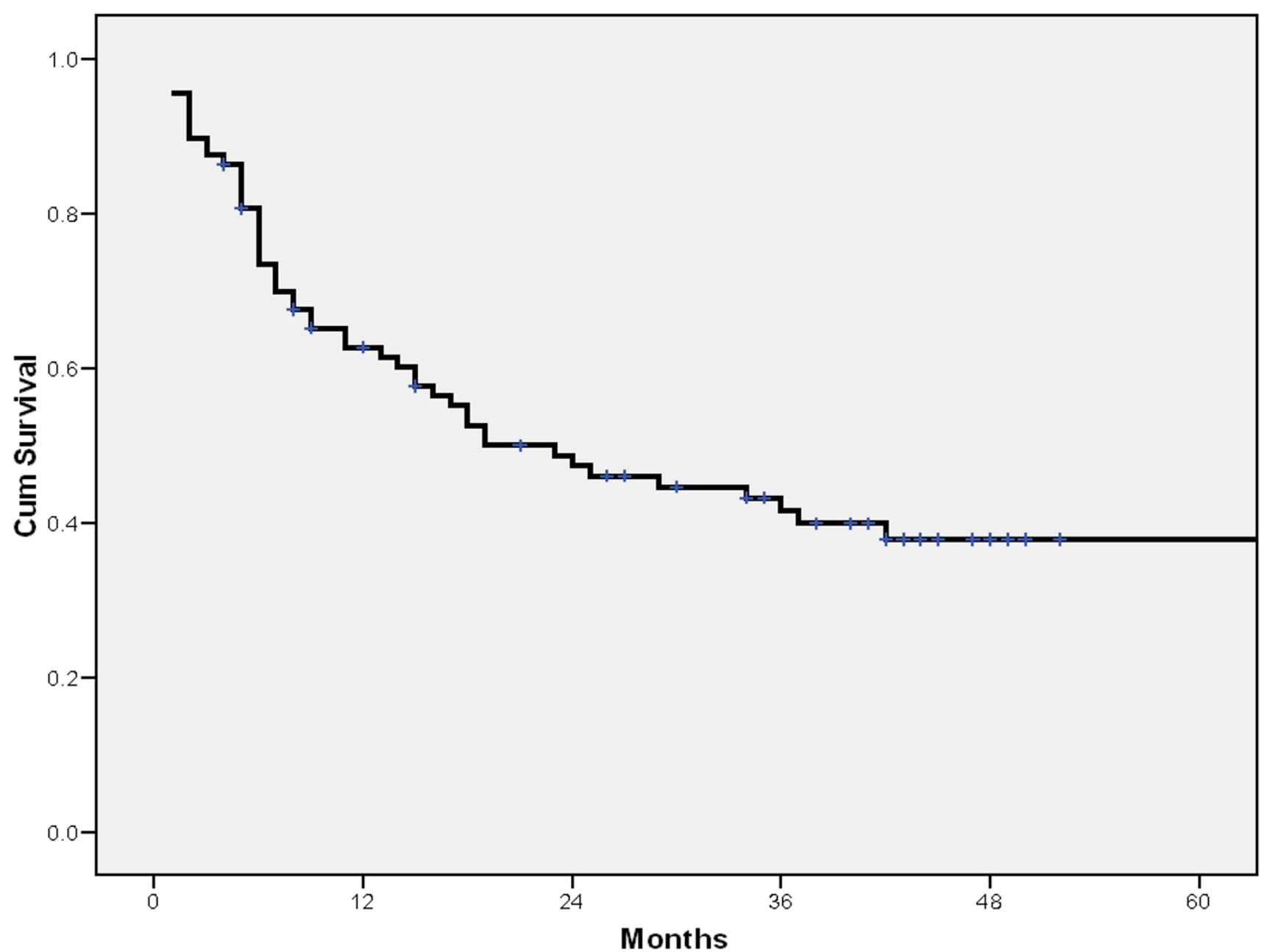

Figure 2

Disease-free survival.

Table 3: Disease-free intervals

\begin{tabular}{|c|c|c|c|c|c|c|}
\hline \multicolumn{7}{|c|}{ disease free interval (months) } \\
\hline & mean & SE & $95 \% \mathrm{Cl}$ & median & SE & $95 \% \mathrm{Cl}$ \\
\hline overall & 34.4 & 3.2 & $28.0-40.77$ & 19.0 & 6.31 & $6.62-31.38$ \\
\hline locrelapse-free & 55 & 3.3 & $48.49-61.52$ & $*$ & $*$ & $*$ \\
\hline dist. relapse-free & 41.6 & 3.5 & $34.83-48.42$ & $*$ & $*$ & $*$ \\
\hline
\end{tabular}




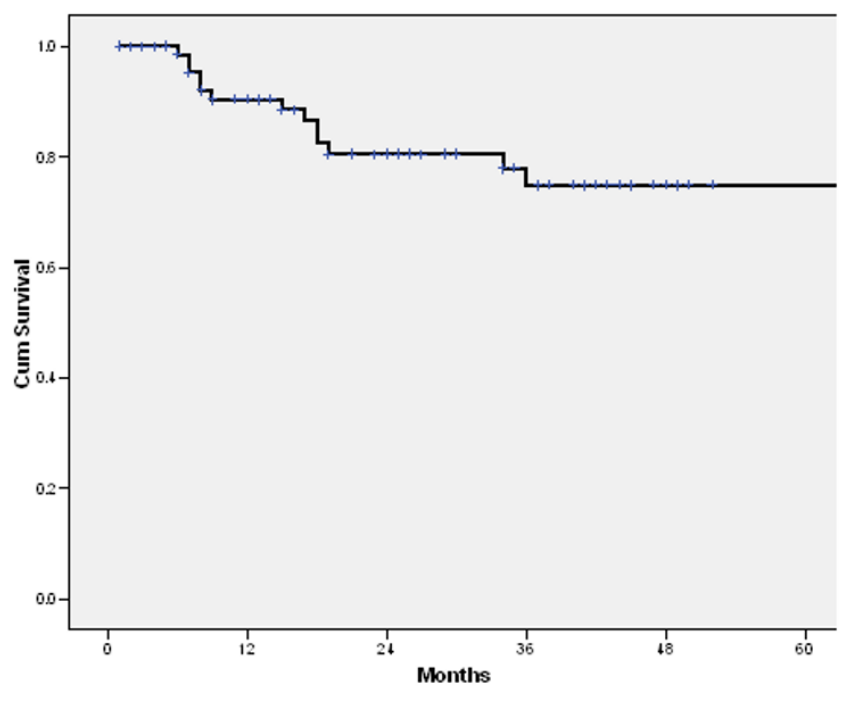

a)

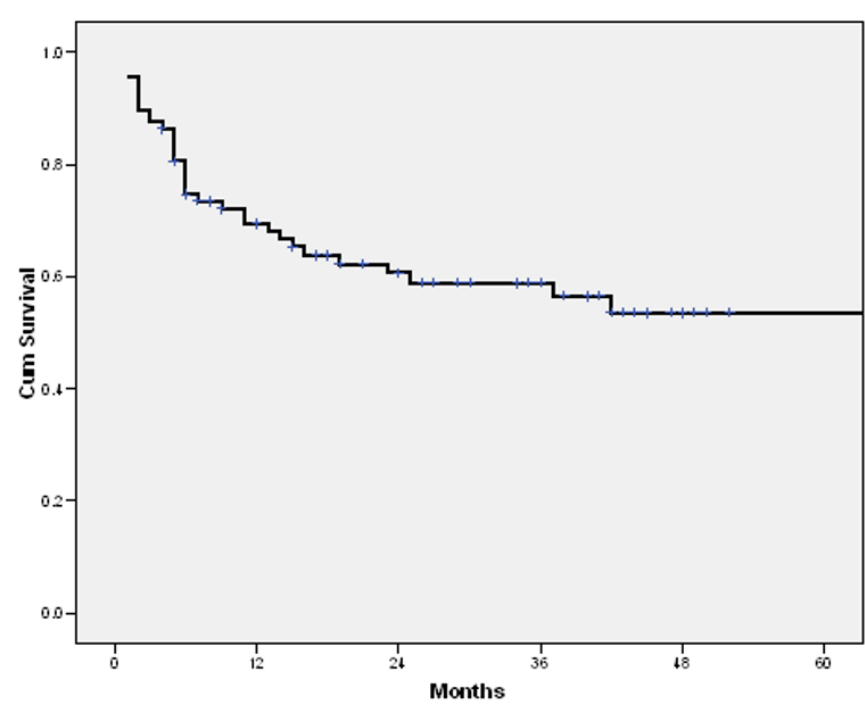

b)

\section{Figure 3}

Locoregional (a) and distant (b) relapse-free survival.

Related to the relapse occurrence, although radiographic aspect and extent of resection followed the same trend as in the survival analysis, only $\mathrm{T}$ stage and $\mathrm{N}$ stage were found as significant in the same sense as for survival.

On multivariate, only $\mathrm{T}$ and $\mathrm{N}$ stage were found as significant in terms of survival.

\section{Discussion}

The main point of the present study is reliability of data owing to regular short interval contacts with patients. So, the obtained relapse pattern can be considered highly reli-

Table 4: Relapse during the first postoperative year

\begin{tabular}{|c|c|c|c|c|c|c|}
\hline \multirow{3}{*}{$\begin{array}{c}\text { disease-free interval } \\
\text { (months) }\end{array}$} & \multicolumn{2}{|c|}{$<3$} & \multicolumn{2}{|c|}{ 3-6 } & \multicolumn{2}{|c|}{$>6$} \\
\hline & $\mathbf{n}$ & $\%$ & $\mathbf{n}$ & $\%$ & $\mathbf{n}$ & $\%$ \\
\hline & 10 & 33.3 & 12 & 40 & 8 & 26.7 \\
\hline & \multicolumn{6}{|c|}{ interval operation-relapse } \\
\hline & \multicolumn{3}{|c|}{$<$ I year } & \multicolumn{3}{|c|}{$>$ I year } \\
\hline Tu diameter $(\mathrm{mm})$ & \multicolumn{3}{|c|}{$79 \pm 32$} & \multicolumn{3}{|c|}{$63 \pm 19.8$} \\
\hline N2 (\%) & \multicolumn{3}{|c|}{40.6} & \multicolumn{3}{|c|}{22.2} \\
\hline$P$ value & \multicolumn{6}{|c|}{ Rtu: > 0.065; N2: 0.39} \\
\hline
\end{tabular}

able and pure, i.e. uninfluenced by nonsurgical treatment owing to the absence of patients with neoadjuvant treatment. This could justify such a study design and expected practical benefit. Moreover, although several factors have been shown to affect survival, few studies have demonstrated any correlation between these factors and tumor recurrence. In fact, most studies focused on survival as end point [4-6].

The type of lymphadenectomy in the present study was complete removal of all palpable and visible lymph nodes. Most of our patients had seven or more groups of lymph node stations harvested. It was clearly demonstrated that, after less than 4, 4-6, 7-9 nodes harvested, the corresponding 5-year disease-free survival rates were $43.4 \%, 67.3 \%$ and $76.3 \%$ respectively [7]. It was also recently shown that sampling adequately recognized N2 disease and multilevel N2 lesions in only $52 \%$ and $40 \%$ patients respectively [8]. A certain recently expressed concerns related to the influence of tumor side (the aforementioned advantages of dissection could not always be confirmed in presence of left sided tumors) [9], did not influence our current policy of lymphadenectomy.

The reason for particularly analyzing $\mathrm{T} 2$ descriptors lies in the results of some recent studies which found visceral pleural involvement as significant prognostic factor [10]. Despite the nearly equal percent of mediastinal lymph node metastases in our patients with and without visceral pleural involvement, a clear trend of survival worsening 


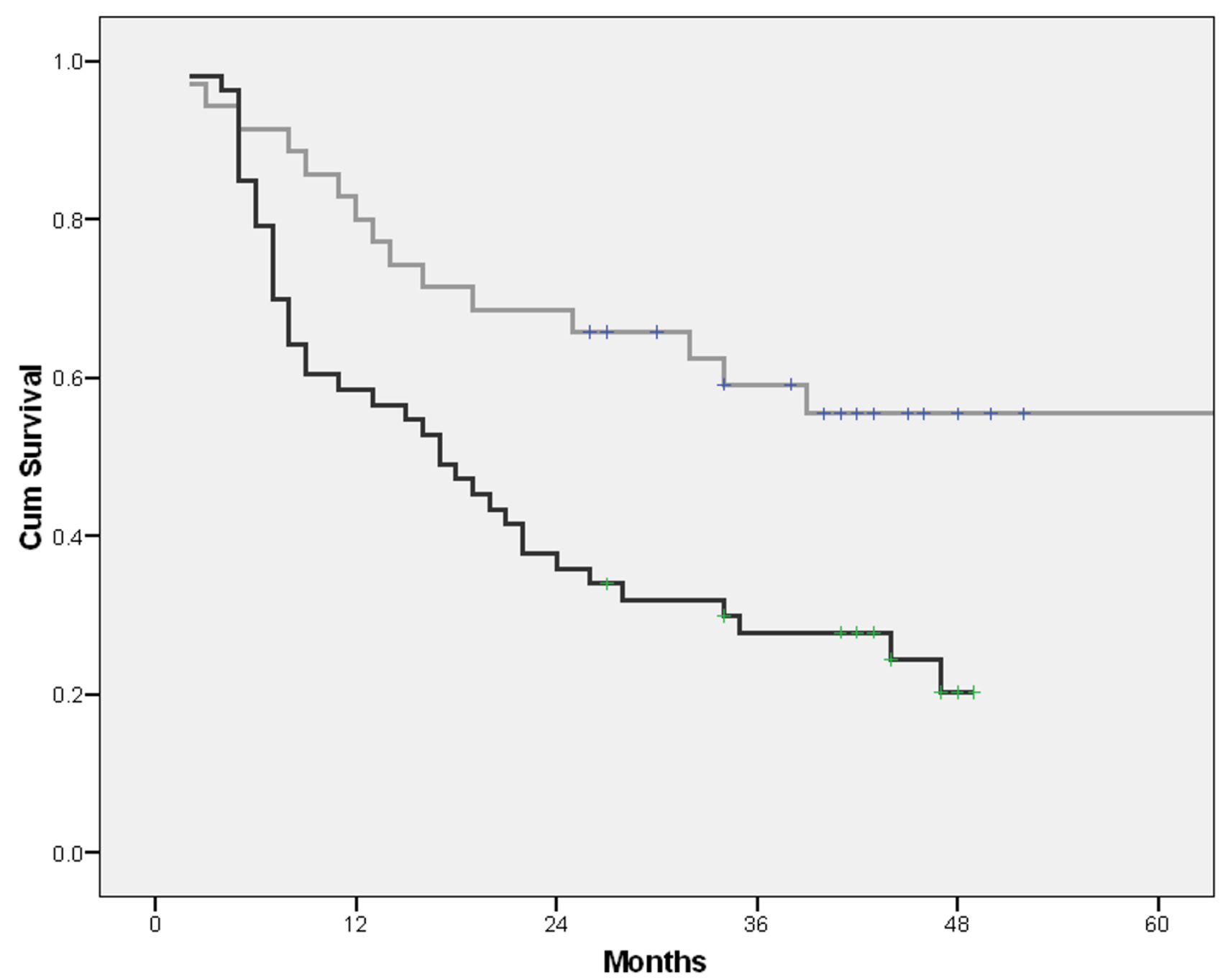

Figure 4

Survival depending on the extent of resection (gray line: lobectomy, black line: pneumonectomy).

was found if the visceral pleura was invaded. However, due to the absence of statistical significance (median survival $34 \pm 7$ vs. $26 \pm 7$ months), our results are in line with studies demonstrating that, even in the stage I, the prognostic significance of non-size based T2 descriptors depends on tumor size. By the other hand, it was clearly shown that, by not taking account of different T2 descriptors, as many as $21.1 \%$ of the stage IB patients may be unnecessarily upstaged from stage IA to stage IB as their survival was not different from that of stage IA patients [11].

The causes of a quite high relapse rate (56.8\%) in the present study during the follow up period can be discussed from several aspects. First, the predominance of distant vs. locoregional type is an expected finding, usually explained by the variability in the pattern of lym- phatic drainage and an incidence of skip metastases of 31$74 \%$ [12]. Moreover, microscopic metastases in the N1 and N2 nodes are often below the limits of detection by PET $[13,14]$. Second, in the majority of our patients with relapse (30/50), relapse occurred inside the first 12 months after the operation, in 22/30 less than 6 months after the operation. Such a finding clearly indicates the existence of distant metastases in these patients at the time of the operation, thus supporting the evidence of distant metastases at the moment of operation as one of major causes of understaging, even in the stage I [15]. Third, greater tumour diameter in our patients with relapse during the first 12 months vs. patients with later relapse (79 \pm 32 vs. $63 \pm 19.8 \mathrm{~mm}$ ) underlines the role of the tumour diameter, thus supporting observations that there is a three-fold increase in the risk of having pathologic stage II or stage III disease with every $1.0 \mathrm{~cm}$ increase in tumor 
Table 5: Univariate and multivariate analysis of factors influencing survival and relapse

\begin{tabular}{|c|c|c|c|c|c|c|c|c|c|c|}
\hline & & \multicolumn{6}{|c|}{ UNIVARIATE } & \multirow{2}{*}{\multicolumn{3}{|c|}{$\begin{array}{c}\text { MULTIVARIATE } \\
\text { survival }\end{array}$}} \\
\hline & & \multicolumn{3}{|c|}{ survival (months) } & \multicolumn{3}{|c|}{ relapse free interval (months) } & & & \\
\hline & & median & $95 \% \mathrm{Cl}$ & $P$ & median & $95 \% \mathrm{Cl}$ & $P$ & SE & df & sig. \\
\hline Rtg aspect & $\begin{array}{r}\text { Tumour } \\
\text { other categories) }\end{array}$ & $\begin{array}{l}44 \\
16\end{array}$ & $\begin{array}{l}26.12-61.88 \\
8.59-23.41\end{array}$ & 0.0289 & $\begin{array}{l}42 \\
15\end{array}$ & $\begin{array}{l}32.16-51.84 \\
7.15-22.85\end{array}$ & 0.0557 & 0.361 & 1 & 0.743 \\
\hline T component & $\begin{array}{r}<\mathrm{T} 3 \\
\mathrm{~T} 3\end{array}$ & $\begin{array}{l}34 \\
9.0\end{array}$ & $\begin{array}{l}18.77-49.23 \\
3.50-14.50\end{array}$ & 0.0007 & $\begin{array}{c}34 \\
8\end{array}$ & $\begin{array}{l}17.87-50.13 \\
5.92-10.08\end{array}$ & 0.0064 & 0.388 & 1 & 0.002 \\
\hline N component & $\begin{array}{r}<\mathrm{N} 2 \\
\mathrm{~N} 2\end{array}$ & $\begin{array}{l}34 \\
8.0\end{array}$ & $\begin{array}{l}13.70-54.29 \\
5.61-10.39\end{array}$ & 0.001 & $\begin{array}{l}34 \\
6.0\end{array}$ & $\begin{array}{l}14.17-53.82 \\
0.0-13.98\end{array}$ & 0.002 & 0.291 & 1 & 0.019 \\
\hline Extent of resection & $\begin{array}{r}\text { lobectomy } \\
\text { pneumonectomy }\end{array}$ & * & $\stackrel{*}{9.87-24.13}$ & 0.0925 & $\begin{array}{l}36 \\
16\end{array}$ & $\begin{array}{l}23.57-48.13 \\
7.89-24.11\end{array}$ & 0.0925 & 0.477 & 1 & 0.298 \\
\hline $\begin{array}{l}\text { Duration of symptoms } \\
\text { (months) }\end{array}$ & $\begin{array}{l}<3 \\
>3\end{array}$ & $\begin{array}{l}18 \\
32\end{array}$ & $\begin{array}{l}10.67-25.33 \\
30.62-53.46\end{array}$ & 0.0623 & $\begin{array}{l}17 \\
37\end{array}$ & $\begin{array}{l}6.83-27.17 \\
21.28-52.42\end{array}$ & 0.1645 & 0.344 & 1 & 0.180 \\
\hline Bronchoscopic aspect & $\begin{array}{r}\text { normal } \\
\text { pathologic }\end{array}$ & $\begin{array}{l}26 \\
22\end{array}$ & $\begin{array}{l}0.00-54.5 \mid \\
\mid 2.42-31.58\end{array}$ & 0.7294 & $\begin{array}{l}29 \\
19\end{array}$ & $\begin{array}{l}1.91-56.09 \\
8.88-29.12\end{array}$ & 0.6950 & 0.308 & 1 & 0.579 \\
\hline Visceral pleura & $\begin{array}{r}\text { invaded } \\
\text { intact }\end{array}$ & $\begin{array}{l}24 \\
22\end{array}$ & $\begin{array}{l}9.74-38.26 \\
5.88-38.12\end{array}$ & 0.5788 & $\begin{array}{l}36 \\
19\end{array}$ & $\begin{array}{l}25.42-46.58 \\
8.89-29.11\end{array}$ & 0.5094 & 0.362 & 1 & 0.598 \\
\hline
\end{tabular}

*: median not presented (> 50\% alive after 70 months postoperatively)

size [16]. But, it is also true that the diameter after which the risk begins to increase has not still been defined. The association of the greater tumour diameter with higher percentage of $\mathrm{N} 2$ lesions compared with smaller tumours (40.6 vs. $22.2 \%$ ) in our study, represents the reflexion of already described doubling of risk for occult N2 lesions with the increase of the tumour size from $<1 \mathrm{~cm}$ to over 2 $\mathrm{cm}[17]$.

Despite the evidently higher proportion of local relapsefree vs. distant relapse-free patients after the first (90.4 vs. $69.4 \%$ ) and second postoperative year (78.3 vs. 50.5\%), the mean local relapse free and distant relapse free intervals were not significantly different. Nevertheless, this evident difference during the first postoperative year clearly reflects the relatively high percent of patients with early relapse. As most of them had asymptomatic brain and bone metastases, with around a third with more than one metastatic sites, the way of extrathoracic assessment of the disease can be put into question. It is clear that it should be intensified, but based on the obtained results, (mostly because of limited patient number), it is not possible to conclude with certainty in which subset of patients it should be done. It is now well known that the proportion of patients with unexpected extrathoracic metastases varies between 5-29\% and that, even PET scan, (although better than CT and bone scintigraphy in detecting liver and bone metastases) is not a good technique in the search for brain metastases $[18,19]$. Moreover, it was also shown that even the combination of CT, bone scintigraphy, abdominal ultrasonography and PET scan still misses micrometastases in about $20 \%$ of patients [20].

In brief, our expectation that this intensified follow up will help to discover relapse in more asymptomatic patients than without it was not confirmed, because in $88 \%$ of patients the relapse was discovered because of symptoms and only in $12 \%$ at controls. Furthermore, a specific oncological treatment (that could be the end point of this intensified follow up) was performed in only a half of the operated patients. Similarly, the overall survival of patients with relapse discovered by this form of follow up was not different from usually reported rates in the literature. It means that, in this subset of patients, survival is not subject to the influence neither of lead time bias, nor of length time bias, that could cause the false impression of prolonged survival associated with more frequent patients' controls, that sometimes occurs in some screening protocols.

When discussing unexpected relapse in our patients, it should be mentioned that micro metastases to small nodes without mediastinal nodes enlargement is reported to occur in $8-60 \%$ pts. with mediastinal metastases 
$[21,22]$. In the analysed group, relapse occurred in patients with $\mathrm{N} 0$ and $\mathrm{N} 1$ lesions in 30 and $55.6 \%$ patients respectively. Such a finding supports the significance of analysis of extranodal extension, because it was demonstrated that the 5-year survival rate of stage IIIA patients without extranodal extension could be significantly better than that of stage II patients with extranodal extension 30.4 vs. $16.8 \%$ in some series [23]. Beside extranodal extension, a possible cause of at least a part of relapse in presence of $\mathrm{N} 1$ can be due to metastase in nonprimary lobe nodes. Like in our study, metastases in these nodes are not frequently analysed and are reported to occur in up to $30 \%$ patients with lobar lymph nodes metastases [24]. Finally, as the higher proportion of relapse among patients with adenocarcinoma was an expected finding, the grade of tumour differentiation was expected to explain at least a part of the relapse pattern in this study. But, the higher proportion of poorly differentiated tumours in patients with vs. patients without relapse ( $30 \%$ vs. $21 \%$ ), was counterweighed by a smaller proportion of well differentiated tumours in patients without vs. patients with relapse (15.9\% vs. $20 \%)$. Furthermore, as in both groups moderately differentiated tumours were dominant, the influence of this factor (probably because of the limited number of patients) requires further analysis.

Related to the extent of resection, we share the opinion of the authors stating that the analysis of the recurrence rate is likely to be more reasonable than the survival analysis, probably because of the more advanced stage and higher mortality in patients undergoing pneumonectomy. In the present study, despite the clearly longer mean disease free interval in the lobectomy group $(41.1 \pm 5$ vs. $23.38 \pm 2.8$ months), due to the absence of statistical significance, our results are brought in line with those studies which did not confirm significantly different reccurence rate between these two groups [25].

Concerning prognostic factors at univariate analysis, the significant influence of the radiographic aspect (tumour shadows vs. other) was not accompanied by similar role of the bronchoscopic aspect as could be expected and as was demonstrated in some studies with lower local recurrence and higher survival rates associated with positive preoperative bronchoscopic findings. Moreover, although one could expect that aspect other than tumour shadows (atelectasis, hilar masses) could be associated with better survival because of probable existence of more symptoms (secreion retention, hemoptysis), the situation was the opposite in our study. The probable cause is the greater proportion of tumours with diameter $>8 \mathrm{~cm}$ in our group, than in most of the reported series. Nevertheless, this factor was not revealed as significant related to recurrence, just like the influence of the extent of resection, that was discussed above.

The fact that only $\mathrm{T}$ and $\mathrm{N}$ factors were found as significant at multivariate, is not unexpected, once again underlining the role of proper patient selection.

One potential limitation of this study is our intentional omission of the control group. The reason for that is the fact that, even in case controled study, the reliability of data related to many aspects of relapse in any control group, if obtained retrospectively, could cause many biases if compared with the presented relapse pattern obtained in a prospective manner.

As a conclusion, this study showed that the intensified follow up did not increase either the proportion of patients detected with asymptomatic relapse or the number of patients with specific oncological treatment of relapse.

\section{Competing interests}

The authors declare that they have no competing interests.

\section{Authors' contributions}

DS conceived of the study, and participated in its design and coordination; he also operated the majority of patients included in the study. DM participated in the study design; he also operated a part of patients included in the study. GR was in charge for the intensified follow up of operated patients and for the coordination of the study. JS participated in the study design, and was responsible for patohistological diagnosis in all patients included in the study. MG performed the statistical analysis. ME participated in the study design; directly responsable for the immediate and early postoperative course in all patients included in the study. All authors read and approved the final manuscript.

\section{References}

I. Sawyer TE, Bonner JA, Gould PM, Foote RL, Deschamps C, Lange $\mathrm{CM}$, $\mathrm{Li} \mathrm{H}$ : Factors predicting patterns of recurrence after resection of NI Non-Small Cell Lung Carcinoma. Ann Thorac Surg 1999, 68: II71-6.

2. Tanaka F, Yanagihara K, Otake $Y$, Tomoko $Y$, Tsuyoshi S, Ryo M, Kenji I, Wada $\mathrm{H}$ : Prognostic factors in patients with resected pathologic (p-) TI-2NI MO non-small cell lung cancer (NSCLC). Eur J Cardiothorac Surg 200I, 19:555-6I.

3. Osaki T, Nagashima A, Yoshimatsu T, Tashima Y, Yasumoto K: Survival and characteristics of lymph node involvement in patientswith N I non-small cell lung cancer. Lung Cancer 2004, 43:I5I-7.

4. Martini N, Burt ME, Bains MS, McCormack PM, Rusch VW, Ginsberg $\mathrm{RJ}$ : Survival after resection of stage II non-small cell lung cancer. Ann Thorac Surg 1992, 54:460-6.

5. Yano T, Yokoyama H, Inoue T, Asoh H, Tayama K, Ichinose Y: Surgical results and prognostic factors of pathologic NI disease in non-small cell carcinoma of the lung. Significance of $\mathrm{N}$ I level: lobar or hilar nodes. J Thorac Cardiovasc Surg 1994, 107:|398-|402.

6. Ramacciato G, Paolini A, Volpino P, Aurello P, Balesh AM, D'Andrea N, Del Grande E, Passaro U, Tosato F, Fegiz G: Modality of failure 
following resection of stage I and stage II non-small cell lung cancer. Int Surg 1995, 80:156-61.

7. Gajra A, Newman N, Gamble P, Kohman LJ, Graziano SL: Effect of number of lymph nodes sampled on outcome in patients with stage I non-small cell lung cancer. J Clin Oncol 2003, 21:1029-1033.

8. Massard G, Ducrocq X, Kochetkova EA, Porhanov VA, Riquet M: Sampling or node dissection for intraoperative staging of lung cancer: a multicentric cross-sectional study. Eur J Cardiothorac Surg 2006, 30:164-167.

9. Keller S, Adak S, Wagner H, Johnson DH, for the Eastern Cooperative Oncology group: Mediastinal lymph node dissection improves survival in patients with stages II and IIla non-small cell lung cancer. Ann Thorac Surg 2000, 70:358-366.

10. Riquet M, Assouad J, Foucault C, Danel C: Visceral pleura invasion and lung cancer: further clarifications. Eur J Cardiothorac Surg 2004, 25:47I.

II. Ou SHI, Zell JA, Ziogas A, Culver HA: Prognostic Significance of the Non-Size-Based AJCC T2 Descriptors. Visceral Pleura Invasion, hilar Atelectasis, or obstructive pneumonitis in Stage IB Non-small Cell Lung Cancer is dependent on tumor size. Chest 2008, 133:662-669.

12. Schirren J, Bergmann T, Beqiri S, Bolukbas S, Fisseler-Eckhoff A, VogtMoykopf I: Lymphatic spread in resectable lung cancer: can we trust in a sentinel lymph node? Thorac Cardiovasc Surg 2006 , 54:373-380.

13. Marom EM, Sarvis S, Herndon JE, Patz EF Jr: TI lung cancers: sensitivity of diagnosis with fluorodeoxyglucose PET. Radiology 2002, 223:453-459.

14. Cerfolio RJ, Ojha B, Bryant AS, Bass CS, Bartalucci AA, Mountz JM: The role of FDG-PET scan in staging patients with non-small cell carcinoma. Ann Thorac Surg 2003, 76:861-866.

15. Gajra A, Newman N, Gamble GP, Abraham NZ, Kohman LJ, Graziano SL: Impact of tumor size on survival in stage IA non-small cell lung cancer: a case for subdividing stage IA disease. Lung Cancer 2003, 42:5I-57.

16. Veeramachaneni NK, Battafarano RJ, Meyers BF, Zoole JB, Patterson GA: Risk factors for occult nodal metastasis in clinical TINO lung cancer: a negative impact on survival. Eur J Cardiothorac Surg 2008, 33:466-469.

17. Riquet M, Manac'h D, Le Pimpec Barthes F, Dujon A, Debrosse D, Debesse $B$ : Prognostic value of $\mathbf{T}$ and $\mathbf{N}$ in non-small cell lung cancer three centimeters or less in diameter. Eur J Cardiothorac Surg 1997, I I:440-443.

18. Vansteenkiste JF: PET scan in the staging of non-small cell lung cancer. Lung Cancer 2003, 42:S27-S37.

19. Weder W, Schmid RA, Bruchhaus H, Hillinger S, von Schulthess GK Steinert HC: Detection of extrathoracic metastases by positron emission tomography in lung cancer. Ann Thorac Surg 1998, 66:886-892.

20. Stroobants SG, D'Hoore I, Dooms C, De Leyn PR, Dupont PJ, De Wever W, De Groot T, Verschakelen JA, Mortelmans LA, Vansteenkiste JF: Additional value of whole body fluorodeoxyglycose positron emission tomography in the detection of distant metastases of non-small-cell lung cancer. Clin Lung Cancer 2003, 4:242-247.

21. Gross B, Glazer G, Orringer M, Spizarny D, Flint A: Bronchogenic carcinoma metastatic to normal-sized lymph nodes: frequency and significance. Radiology 1988, |66:7|-74.

22. Arita T, Matsumoto T, Kuramitsu T, Kawamura N, Sugi K, Esato K: Is it possible to differentiate malignant mediastinal nodes from benign nodes by size? Reevaluation by CT, transesophageal echocardiography and nodal specimen. Chest 1996, I 1 0:1004-1008.

23. Lee YC, Tu Wu C, Wen Kuo S, Tseng YT, Chang YL: Significance of extranodal extension of regional lymph nodes in surgically resected non-small cell lung cancer. Chest 2007, I 3 I:993-999.

24. Yamanaka S, Hirai T, Takahashi A, Konishi F: Analysis of lobar lymph node metastases around the bronchi of primary and nonprimary lobes in lung cancer. Risk of remnant tumor at the root of the nonprimary lobes. Chest 2002, I 21: I 12-1 I7.

25. Fujimoto T, Cassivi SD, Yang P, Barnes SA, Nichols FC, Deschamps C, Allen MS, Pairolero PC: Completely resected NI non-small cell lung cancer: factors affecting recurrence and long-term survival. J Thorac Cardiovasc Surg 2006, 132:499-506.
Publish with Bio Med Central and every scientist can read your work free of charge

"BioMed Central will be the most significant development for disseminating the results of biomedical research in our lifetime. "

Sir Paul Nurse, Cancer Research UK

Your research papers will be:

- available free of charge to the entire biomedical community

- peer reviewed and published immediately upon acceptance

- cited in PubMed and archived on PubMed Central

- yours - you keep the copyright 